Check for updates

Cite this: RSC Adv., 2019, 9, 32581

\title{
Cyanobacterial promoted enrichment of rare earth elements europium, samarium and neodymium and intracellular europium particle formation $\dagger$
}

\author{
Christian B. Fischer, (D) *ab Susanne Körsten, ${ }^{a}$ Liz M. Rösken, ${ }^{a}$ Felix Cappel, ${ }^{a}$ \\ Christian Beresko, ${ }^{c}$ Georg Ankerhold, (D) ${ }^{c}$ Andreas Schönleber, (D) d Stefan Geimer, ${ }^{e}$ \\ Dennis Ecker ${ }^{\dagger}$ and Stefan Wehner ${ }^{a}$
}

In the recovery of rare earth elements (REE) microbial biosorption has shown its theoretical ability as an extremely economically and environmentally friendly production method in the last few years. To evaluate the ability of two cyanobacterial strains, namely Anabaena spec. and Anabaena cylindrica to enrich dissolved trivalent REE, a simple protocol was followed. The REE tested in this study include some of the most prominent representatives, such as europium (Eu), samarium ( $\mathrm{Sm}$ ) and neodymium ( $\mathrm{Nd}$ ). Within the experiments, a fast decrease of the $\mathrm{REE}^{3+}$ concentration in solution was tracked by inductively coupled plasma mass spectrometry (ICP-MS). It revealed an almost complete (>99\%) biosorption of $\mathrm{REE}^{3+}$ within the first hour after the addition of metal salts. $\mathrm{REE}^{3+}$ uptake by biomass was checked using

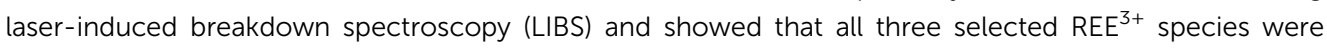
enriched in the cyanobacterial biomass and the process is assigned to a biosorption process. Although the biomass stayed alive during the experiments, up to that, a distinction whether the $\mathrm{REE}^{3+}$ was intraor extracellularly sorbed was not possible, since biosorption is a metabolism independent process which occurs on living as well as non-living biomass. For europium it was shown by TEM that electron dense particles, presumably europium particles with particle sizes of about $15 \mathrm{~nm}$, are located inside the vegetative cyanobacterial cells. This gave clear evidence that $\mathrm{Eu}^{3+}$ was actively sorbed by living cyanobacteria. $\mathrm{Eu}^{3+}$ biosorption by cell wall precipitation due to interaction with extracellular polysaccharides (EPS) could therefore be excluded. Finally, with XRD analysis it was shown that the detected europium particles had an amorphous instead of a crystalline structure. Herein, we present a fast biosorptive enrichment of the rare earth elements europium, samarium and neodymium by Anabaena spec. and Anabaena cylindrica and for the first time the subsequent formation of intracellular europium particles by Anabaena spec.

Received 21st August 2019

Accepted 3rd October 2019

DOI: $10.1039 / c 9 r a 06570 a$

rsc.li/rsc-advances

\section{Introduction}

In recent years, the use of rare earth elements (REE) has tremendously increased and is thus accompanied by a rising worldwide demand. REE are spent in various modern electronic

\footnotetext{
${ }^{a}$ University of Koblenz-Landau, Campus Koblenz, Department of Physics, Universitätsstraße 1, 56070 Koblenz, Germany. E-mail: chrbfischer@uni-koblenz.de ${ }^{b}$ Mohammed VI Polytechnic University, Materials Science and Nano-Engineering Department, Lot 660, Hay Moulay Rachid, 43150 Benguerir, Morocco

'University of Applied Sciences Koblenz, RheinAhrCampus, Department of Laser Spectroscopy, Joseph-Rovan-Allee 2, 53424 Remagen, Germany

${ }^{d}$ University of Bayreuth, Laboratory of Crystallography, 95447 Bayreuth, Germany ${ }^{e}$ University of Bayreuth, Cell Biology and Electron Microscopy, 95447 Bayreuth, Germany

${ }^{f}$ Federal Institute of Hydrology, Department G2-Aquatic Chemistry, Am Mainzer Tor 1, 56068 Koblenz, Germany
}

$\dagger$ Electronic supplementary information (ESI) available. See DOI: 10.1039/c9ra06570a high tech devices like mobile phones, computers, LCDs and screens as well as for the emerging green technologies, e.g. in wind energy converters, electric cars, energy saving lamps and catalytic converters. Besides, also medicinal applications are known e.g. gadolinium compounds as contrast agent for magnetic resonance imaging and REE as crop fertilizers, which are widely used in agriculture.

As a consequence, REE are heavily exposed from these anthropogenic products to the environment in metallic or even ionic form thus finding an entry to rivers and waste waters. As an example, Kulaksiz and $\mathrm{Bau}^{1,2}$ recently showed that the River Rhine carries considerable amounts of the REE lanthanum, samarium, and gadolinium. As a source, industrial effluents were identified. This means that tons of these REE are likely to reach the North Sea unexploited every year.

The increasing demand for REE thus provides impetus to the development of efficient and environment-friendly recovery methods. Since REE usually are present in small concentrations 
in rivers and in waste waters, methods especially for separating and accumulating these valuable metals from very diluted solutions are necessary. Actually, several procedures like precipitation, ion exchange, electrochemical methods, reverse osmosis and adsorber resins are applied., ${ }^{3,4}$ However, high process costs, environmental impact due to toxic resins or inefficient recovery of highly diluted REE are disadvantageous properties which come along with these common procedures., ${ }^{3,5,6}$

In contrast, the use of (micro-)biological methods gains more and more importance, since they provide alternative, efficient and environment-friendly methods of resource recovery. ${ }^{3,5-7}$ Especially, the uptake of metal ions by microbial biomass (biosorption) is already known, with several bacteria strains even being able to biosorb rare earth metals from diluted solutions. In the area of biological waste water treatment biosorption is already discussed as an efficient process for the bio-removal of heavy metals, e.g. lead and cadmium. ${ }^{8}$ Especially, the recovery of REE metal ions from aqueous solutions with the help of microorganisms is in the focus of current research. For a number of organisms such as bacteria, yeasts and algae this ability was already shown. ${ }^{6,9}$ Adsorption of REE onto the cell walls of Gram-positive bacteria like Bacillus subtilis, Gram-negative bacteria like Escherichia coli, Saccharomyces cerevisiae, several brown algae (sargassum) and many more has been reported. ${ }^{3,10-14}$

Among the various microorganisms studied, also cyanobacterial strains proved to be highly capable to biosorb and accumulate dissolved (heavy) metals as well as REE. Kim et al. ${ }^{15}$ used Phormidium, a genus of filamentous cyanobacteria, to adsorb various REE (La, Pr, Nd, Sm, Gd, Dy) from an ore leachate. With the dead biomass used in this study they found a fast biosorption which occurred for a short time at an early stage. The interaction of micromolar solutions of $\left[\mathrm{UO}_{2}\left(\mathrm{CO}_{3}\right)_{2}\right]^{2-}$ with the cyanobacterial strain Anabaena torulosa was investigated by Acharya et al. ${ }^{16}$ They showed the importance of cell viability for optimal uranyl binding. Heat killed cells or extracts of the extracellular polysaccharides exhibited only limited binding of uranyl.

Adsorption of ionic species is mainly attributed to the binding to functional groups on the outer cell wall or more precisely the exocellular polysaccharidic layers (sheath, capsule and mucilage). Especially, exopolysaccharide (EPS) producing cyanobacteria are very efficient in binding heavy metal ions, thus being promising candidates for the removal of positively charged metal ions from aqueous solutions. ${ }^{17}$ Okajima et al. ${ }^{18,19}$ for instance, extracted the polysaccharide sacran from cyanobacterium Aphanothece sacrum. They investigated the sorption efficiency of sacran-containing hydrogels towards $\mathrm{Nd}^{3+}$ and observed that the gels sorbed excessive amounts of $\mathrm{Nd}^{3+}$, in addition being more efficient than conventional alginate-containing gels.

Besides, bioaccumulation, i.e. the active intracellular accumulation of the ionic metal species may occur in cyanobacteria. As this is a plasma membrane mediated transport of metal ions into cellular compartments, ${ }^{8}$ it requires living cells for the intracellular enrichment and is often associated with a defense mechanism of the cell towards a toxic metal. ${ }^{20}$ The "detoxification" of the mobile metal species may than proceed by chemical conversion in the cytoplasma via transformation of the oxidation state, precipitation of metal ions by cell contents (biomacromolecules), enzymatically driven redox reactions or a combination of them. Especially cyanobacteria are known to produce metal-binding proteins in the cytoplasma, e.g. cysteinerich metallothioneins, in response to the presence of metal ions, which sequester them in biologically inactive, non-celltoxic forms. ${ }^{21}$ Although the interaction of metallothioneins with heavy metals such as cadmium, zinc and copper are widely described in the literature, ${ }^{22-25}$ these proteins are also capable of binding trivalent REE metal ions such as $\mathrm{La}^{3+} \cdot{ }^{26}$ Interestingly, the interaction of metal ions with metallothioneins can furthermore lead to a nanocluster formation as described for in vitro experiments with gold by Mercogliano and DeRosier. ${ }^{27}$

Some cyanobacteria are able to reduce the biosorbed metal ions to their zero-valent state (bioreduction) by enzymatic redox reactions and finally to accumulate them intra- or extracellular as crystalline nanoparticles in vivo. This is frequently shown for noble metals like gold, silver, palladium or platinum. Brayner et $a .^{28}$ examined three different cyanobacteria strains, namely Anabaena flos-aquae, Calothrix pulvinata, and Leptolyngbya foveolarum, with respect to their ability to biosynthesize Au-, Ag-, Pd-, and Pt-nanoparticles. All three strains studied, succeeded in the extracellular formation of gold- and silver-nanoparticles, respectively, with final particle sizes from 5-12 and 15-40 nm. The size as well as the amount of nanoparticles formed was found to be dependent on the strain used. Due to a high number of heterocysts, Anabaena flos-aquae has shown a high concentration of the enzyme nitrogenase and produced therefore in a few minutes well-defined nanoparticles. Dahoumane et al. ${ }^{29}$ stated a high gold adsorption rate for Anabaena flos-aquae that however comes along with a wide size distribution of nanoparticles produced as well as a fast cell death.

In recent studies Anabaena spec. ${ }^{30}$ and Anabaena cylindrica ${ }^{31}$ were used to study the time-dependent growth of crystalline $\mathrm{Au}^{0}$ nanoparticles from diluted $\mathrm{Au}^{3+}$ solutions. In contrast to Anabaena flos-aquae, both Anabaena spec. and Anabaena cylindrica, do not produce any toxic anatoxin-a, ${ }^{32}$ which is a major advantage featuring environmentally friendly metal bio-recovery as well as nanoparticle biosynthesis. Gold nanoparticles with average sizes of 9 and $10 \mathrm{~nm}$, respectively, in both species mainly located at the thylakoid membranes of the vegetative cells rather than in heterocysts were already found after two hours and four hours, respectively. One of them even shows selective biosorption and biosynthesis of gold nanoparticles from multimetal solutions. ${ }^{32}$

In contrast to the above mentioned nanoparticle formation of noble metals, a conversion of mobile REE (ions) into insoluble forms, in the manner of REE particles or REE nanoparticles by living cyanobacteria was not presented yet. Up to now, only REE biosorption, as described above, is known for some cyanobacteria.

Herein, we present a fast biosorptive enrichment of the rare earth elements europium, samarium and neodymium by Anabaena spec. and Anabaena cylindrica and for the first time the subsequent formation of intracellular europium particles by Anabaena spec. 


\section{Experimental}

Materials and culture conditions of cyanobacteria and metal incubation experiments

The photosynthetic organisms with the ability to biosorb and bioreduce diluted metal ions to their zero-valent form previously shown for gold ${ }^{\mathbf{3 0 , 3 1}}$ - were selected: cyanobacteria strains Anabaena spec. (SAG 12.82) and Anabaena cylindrica (SAG 1403.2) were purchased from the Culture Collection of Algae (SAG) Göttingen, Germany. The respective cultures were grown in pre-sterilized $250 \mathrm{~mL}$ Erlenmeyer flasks each containing $150 \mathrm{~mL}$ modified Bold's Basal Medium (BBM, pH 6.8), unless otherwise stated. Modification was done by reducing the nitrate concentration down to $50 \%$, since less nitrate concentration leads to an increased heterocyst formation. During cultivation the cultures were shaken continuously with an orbital shaker and were placed in a temperature controlled incubator with adjustable light intensity. The general conditions were $22{ }^{\circ} \mathrm{C}$ and the specific pH-value of these cultures is 7.3 , and daylight spectrum with a color of $4200 \mathrm{~K}$ in a $12 \mathrm{~h}$ day night rhythm.

Appropriate cultures were divided in half. The one part was incubated with the individual concentration of the respective REE salt (general formula: $\operatorname{REE}\left(\mathrm{NO}_{3}\right)_{3} \cdot 6 \mathrm{H}_{2} \mathrm{O}$; $\mathrm{ABCR} \mathrm{GmbH}$, Karlsruhe, Germany) dissolved in modified BBM. The initial concentrations were as follows: $0.111 \mathrm{mM}$ and $0.191 \mathrm{mM} \mathrm{Eu}^{3+}$ respectively, $0.139 \mathrm{mM} \mathrm{Sm}^{3+}$ and $0.103 \mathrm{mM} \mathrm{Nd}^{3+}$. The second part of respective cultures was left untreated and therefore taken as a reference.

At given times an aliquot volume of $2 \mathrm{~mL}$ was taken from each flask and processed differently based on the intended type of analysis, namely inductively coupled plasma mass spectrometry (ICP-MS), laser-induced breakdown spectroscopy (LIBS), X-ray diffraction (XRD) or transmission electron microscopy (TEM). Biomass was collected and separated from media by centrifugation ( $14000 \mathrm{rpm}, 15$ minutes) and washed thoroughly with deionized water. Since the first centrifugation step takes at least 15 minutes we assume for all data points a temporal uncertainty of \pm 10 minutes, since interaction (uptake, exchange, etc.) has been stopped any time between taking the sample from the flask and separating the biomass from the supernatants after centrifugation. Scheme 1 illustrates the individual steps described above for better understanding.

\section{Inductively coupled plasma mass spectrometry (ICP-MS)}

ICP-MS is used for determining trace and multi-element analysis and ideal for aqueous media, since the majority of target compounds can be detected below $0.1 \mathrm{mg} \mathrm{\textrm {L } ^ { - 1 } , 3 3 - 3 5}$ means in a ppt to ppm concentration range. Here, samples for ICP-MS analysis are based on (A) the respective pristine REE stock solution with its initial concentration being in appropriate dilution in comparison to the biomass-containing experiments and (B) the supernatant media of the respective incubation experiment separated from a biomass-containing aliquot to analyze the decrease of REE concentration in the solution due to ongoing sorption by biomass.
The concentration of the respective REE in the supernatant was measured by ICP-MS (7700, Agilent Technologies, Japan). Therefore, the supernatant and the biomass were separated by centrifugation at $14000 \mathrm{rpm}$, followed by immediate storage at $-20{ }^{\circ} \mathrm{C}$. Before deep freezing, the supernatant has been sterile filtered over $0.45 \mu \mathrm{m}$ and treated with $20 \mu \mathrm{L}$ concentrated $\mathrm{HNO}_{3}$ to keep the actual concentration of metal ions stable. After completion of the experimental series, the samples were thawed at room temperature. An aliquot of $1 \mathrm{~mL}$ was transferred to a $\mathrm{HNO}_{3}$ rinsed sample tube and diluted with $3 \mathrm{~mL}$ bi-distilled water to a total volume of 4 mL. Afterwards, the metal concentration of the REE in the different samples was measured by means of ICP-MS. The difference of the metal concentration between the start of incubation and taking the sample was taken as a measure of the amount of metal uptake by the cyanobacterial cells.

\section{Laser-induced breakdown spectroscopy (LIBS)}

For LIBS measurements, the separated biomass was dried and placed without any further processing in the apparatus. A LIBS micro-plasma was produced with a homemade setup from commercially available components. The procedure was previously described $^{31}$ in more detail. In general, the LIBS setup consists of a pulsed laser Nd:YAG laser (CryLas, model DSS1064-3000) at a wavelength of $1064 \mathrm{~nm}$ and a pulse energy of $2.5 \mathrm{~mJ}$ with a pulse duration of $2 \mathrm{~ns}$ (FWHM), and CzernyTurner spectrometers (Ocean Optics, models MAYA 2000 Pro and USB2000). The emitted light of the laser-induced plasma on the sample's surface was analyzed by spectrometers and processed by a self-programmed software tool based on the LabVIEW software package (National Instruments). The data shown here are signals summed up over 100 individual measurements. Qualitative elemental analysis is performed by tracking element specific characteristic peaks as listed in referred databases. ${ }^{36}$ An absolute quantitative analysis of LIBS spectra is only known for bulk materials and liquids for trace element analysis ${ }^{37-39}$ and could therefore not be performed in the current experiments.

\section{X-ray powder diffraction (XRD)}

Samples for XRD analysis are based on the biomass separated from an aliquot. A detailed description of this process was previously ${ }^{31}$ given. Finally, the biomass was placed as thin and as homogeneous as possible on a homemade sample holder. The sample holder consists of a $1 \mathrm{~mm}$ thick and $25 \mathrm{~mm}$ diameter $\mathrm{Si}(977)$ single crystal mounted in a $32 \mathrm{~mm}$ diameter and $4 \mathrm{~mm}$ thick plate of polycarbonate, which fits directly to the support of the Phillips X-pert diffractometer employed for the Xray diffraction measurements.

\section{Transmission electron microscopy (TEM)}

Biomass transmission electron microscopy (TEM) imaging was performed using a JEM-2100 transmission electron microscope (JEOL, Tokyo, Japan) operated at $80 \mathrm{kV}$. Micrographs were taken using a $4080 \times 4080$ pixels charge-coupled device camera (UltraScan 4000, Gatan, Pleasanton, CA, USA) and Gatan DigitalMicrograph software (version 1.85.1535). To reveal the spatial distribution of the particles within the various cells, samples 
were chemically fixed using glutaraldehyde and osmium tetroxide, dehydrated and embedded in epoxy resin according to standard procedures. Ultrathin sections of about $60 \mathrm{~nm}$ thickness were prepared using an Ultracut EM UC6 ultramicrotome (Leica Microsystems, Wetzlar, Germany) with a diamond knife (type ultra $35^{\circ}$, Diatome, Biel, Switzerland). Sections were collected on Pioloform-coated copper slot grids (Plano, Wetzlar, Germany) and stained with uranyl acetate and lead citrate according to established procedures ${ }^{\mathbf{4 0}}$ before imaging. A detailed description ${ }^{31}$ of the method was previously given.

\section{Image processing}

Based on the registered scale bar in the TEM images, the dimension of a pixel was calculated in square nanometers. The measurements allowed for a reasonable evaluation of the distribution and the average size of the resulting nanoparticles, related to the TEM system used in this study, only for larger particles ( $>3 \mathrm{~nm}$ diameter) and high image magnifications (50 k and more). The identification of all pixels that contribute to a recorded nanoparticles was done according to the procedure previously described by Rochert et al. ${ }^{32}$

\section{Results}

\section{ICP-MS}

ICP-MS analysis was performed on samples taken from the supernatant media starting after metal salt addition. Fig. 1 shows the temporal decrease of REE concentration during incubation of Anabaena spec. and Anabaena cylindrica, respectively, with $\mathrm{Sm}^{3+}, \mathrm{Nd}^{3+}$, and $\mathrm{Eu}^{3+}$ in the time range of some minutes up to more than one day $(28 \mathrm{~h})$.

As can be seen in Fig. 1 the $\mathrm{Eu}^{3+}$ concentration in the supernatant decreased significantly already after less than one hour of incubation from an initial concentration of $0.111 \mathrm{mM}$ to a value of a very low level, which means that more than $98 \%$ of the initial $\mathrm{Eu}^{3+}$ concentration have been removed from the solution. This implies a very fast biosorption process for Anabaena spec. for the low $\mathrm{Eu}^{3+}$ concentration range observed in this study. Within the limit of detection and the error margins, only the very little amount of $76 \mathrm{ppb}$, i.e. $0.6 \%$ of the initial $\mathrm{Eu}^{3+}$ concentration, was still detected after more than one day (i.e. 28 h). This indicates the uptake of almost the entire $\mathrm{Eu}^{3+}$ amount added to the biomass after that time. From the data shown, it

\section{Cultivation of Cyanobacteria}

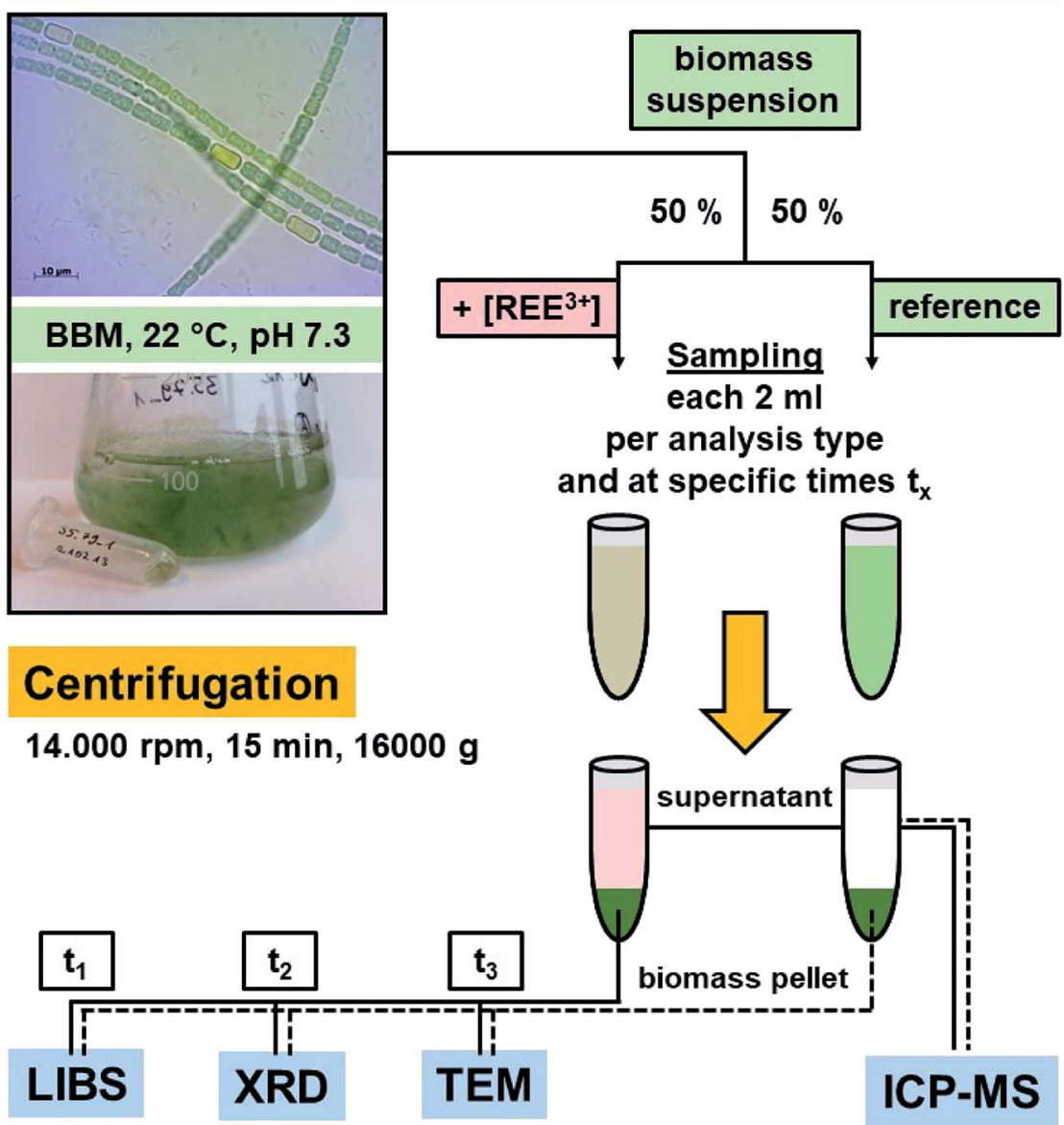

\section{Characterization with consistent preparation}

Scheme 1 Sampling of cyanobacteria cultures for specific characterization methods. 


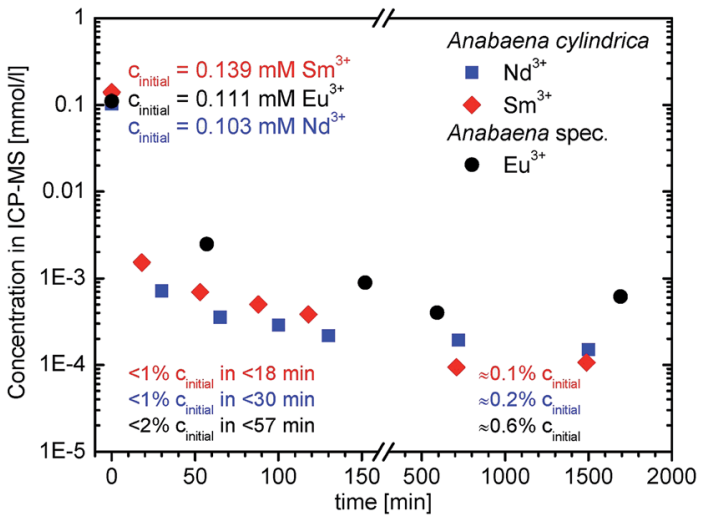

Fig. 1 Time dependent decrease of $\mathrm{REE}^{3+}$ concentration present in supernatant after incubation of Anabaena spec. and Anabaena cylindrica with an overall concentration of $0.111 \mathrm{mM} \mathrm{Eu}^{3+}$ (black dots), $0.139 \mathrm{mM} \mathrm{Sm}^{3+}$ (red diamonds) and $0.103 \mathrm{mM} \mathrm{Nd}^{3+}$ (blue squares), respectively. First data point at 0 minutes means the initial $\mathrm{REE}^{3+}$ concentration of the added stock solution in appropriate dilution without biomass $\left(c_{\text {initial }}\right)$ (See ESI† for more details).

can also be concluded, that no re-release of previously biosorbed europium ions back into the surrounding media occurs during the observed period. A possible reduction of $\mathrm{Eu}^{3+}$ concentration in the media due to possible competing precipitation reactions is unlikely, as no precipitate formation was noted during the experiment. A precipitation-based misinterpretation of the ICP-MS data can thus be excluded.

The present setup, which requires pipetting and centrifugation (biomass/supernatant separation) of each sample, leads to the limitation of temporal uncertainty and quite long sampling intervals. Therefore, no time intervals between two data points shorter than 25 minutes could be arranged. In order to shorten sampling times and especially to reveal the first few minutes of uptake an improved setup and experimental design is required.

Additional experiments with Anabaena spec. cultures grown without nutrients and incubated with higher europium concentrations were also accepted and tolerated by the cultures for several days (see Fig. 2). These experiments with an almost twice as high $\mathrm{Eu}^{3+}$ concentration of $c=0.191 \mathrm{mM}$, gave similar results to the ones described before. The ICP-MS measurements revealed that a reduction of $\mathrm{Eu}^{3+}$ concentration by about $75 \%$ to approximately $0.05 \mathrm{mM}$ was already achieved after 40 minutes. A further decrease to an almost $90 \%$ uptake of dissolved europium was determined after 65 minutes and this concentration remained almost constant within the error margins for subsequent measurements. A renewed slight increase (up to $0.04 \mathrm{mM}$, i.e. $20 \%$ of initial of $\mathrm{Eu}^{3+}$ concentration) in the supernatant for longer sampling times ( $28 \mathrm{~h}$ ) was observed. This may be due to a release of solely bound $\mathrm{Eu}^{3+}$ as a consequence of starving cultivation. It seems that a nutrient-rich and fed growth of Anabaena spec. is beneficial towards an efficient $\mathrm{Eu}^{3+}$ uptake, while starving leads to a reduced biosorption capability.

These findings lead us to check in addition the biosorption capabilities regarding other rare earth elements, e.g. samarium and neodymium. For these experiments we used a cyanobacterial strain which is closely related to Anabaena spec., namely

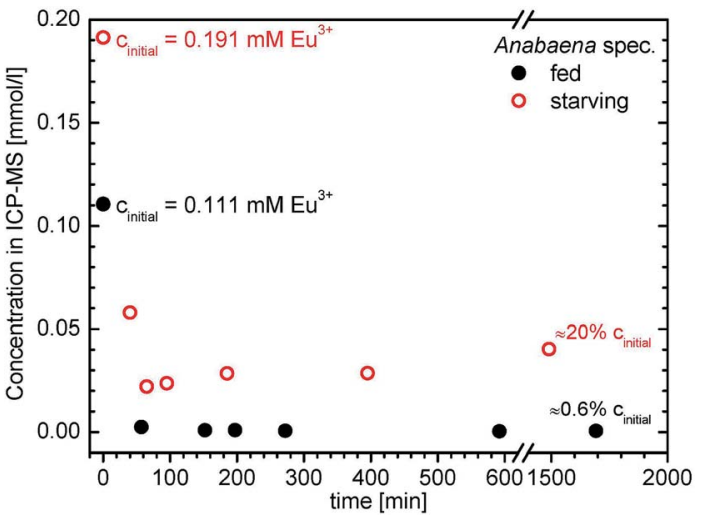

Fig. 2 Time dependent decrease of $\mathrm{Eu}^{3+}$ concentration present in supernatant after incubation of two Anabaena spec. cultures with an overall concentration of $0.191 \mathrm{mM} \mathrm{Eu}^{3+}$ and $0.111 \mathrm{mM} \mathrm{Eu}^{3+}$, respectively. The two series differ in their growth conditions: one was starving (red open circles), i.e. grown without any nutrients, and the other one (black filled circles) was fed in the usual manner. First data point at 0 minutes means the initial $\mathrm{Eu}^{3+}$ concentration of the added stock solution in appropriate dilution without biomass (See ESI† for more details).

Anabaena cylindrica which was grown in nutrient media. Due to the results from the previous europium experiments, ICP-MS analysis was performed starting already after 20 minutes of REE addition. With this it was intended to show a continuous decrease with time, but since sampling time cannot be further accelerated or timely resolved to an accuracy of minutes, 20 minutes is more or less the earliest possible sampling time in these experiments.

In Fig. 1 the decrease of samarium concentration during incubation of Anabaena cylindrica with $\mathrm{Sm}^{3+}$ for more than one day is shown. Although the sampling times were accelerated, i.e. the first sample was taken within 20 minutes, the samarium concentration had already decreased in an impressive manner. The amount of samarium in the supernatant dropped from an initial concentration of $0.139 \mathrm{mM} \mathrm{Sm}^{3+}$ to a very low value of $c=$ $1.52 \times 10^{-3} \mathrm{mM}$ within these very first minutes of the experiment. This means, that after the first 20 minutes less than $1 \%$ of the initial samarium concentration was detected in the media. Measurements of subsequent samples revealed that the concentration in the supernatant was still slowly decreasing for several hours. Longer time scales (up to 58 days) have also been analyzed (data not shown here), but did not show any significant changes. Finally, comparable results were obtained for the added neodymium $\left(c_{\text {initial }}=0.103 \mathrm{mM} \mathrm{Nd}^{3+}\right)$ to an Anabaena cylindrica culture. More than $99 \%$ of neodymium was removed as well from the solution within 30 minutes after metal salt addition (compare Fig. 1).

During the incubation experiments the cultures were visually controlled regularly and followed by optical microscopy (Axioskop 50, Zeiss) to examine the cells' vitality. Throughout the experiment the culture stays vital and constantly a high fraction of living organisms with the typical appearance and shape of Anabaena spec. and Anabaena cylindrica, respectively, were found. Both consist of long vegetative cell chains (length up to 
more than $100 \mu \mathrm{m}$, diameter around $3 \mu \mathrm{m}$ ), appearing green, and anywhere between there are heterocysts, which are larger, have a thicker cell wall and appear lighter because they contain less to no chlorophyll in the cells.

Moreover, no changes in color neither of the cells (no color fading due to loss of vitality) nor of the supernatant (due to a precipitation or a release of particles) appeared after $\mathrm{REE}^{3+}$ incubation. This means the chosen $\mathrm{REE}^{3+}$ concentrations ranging from $0.103 \mathrm{mM}$ up to $0.191 \mathrm{mM}$ are not toxic to the cyanobacteria and neither precipitation nor a particle release in the surrounding media occurs.

\section{LIBS}

With ICP-MS it was shown that $\mathrm{REE}^{3+}$ concentration was removed from aqueous media after addition to the cyanobacteria Anabaena spec. and Anabaena cylindrica checking the supernatant separated from biomass. To evidence the uptake and enrichment of REE in the biomass, LIBS was used. Therefore, biomass samples were taken from supernatant at certain times after $\mathrm{REE}^{3+}$ addition, separated and analyzed.

LIBS spectra of dried biomass samples of Anabaena spec. after 6.5 hours (black line) of incubation time with an initial concentration of $0.191 \mathrm{mM} \mathrm{Eu}^{3+}$ are shown in Fig. 3. Additionally, the LIBS spectrum, obtained from the pristine $\mathrm{Eu}\left(\mathrm{NO}_{3}\right)_{3} \cdot 6 \mathrm{H}_{2} \mathrm{O}$ (grey line) is presented, used as the $\mathrm{Eu}^{3+}$ source in the incubation experiments. Specific signals which refer to europium (according to NIST database ${ }^{36}$ ) are clearly seen, namely the signals at $368.6 \mathrm{~nm}, 372.2 \mathrm{~nm}, 381.7 \mathrm{~nm}, 390.3 \mathrm{~nm}$, $392.7 \mathrm{~nm}$ and $396.9 \mathrm{~nm}$.

In Fig. 3 the signals being characteristic for europium shown in the grey colored reference spectra can be found in all incubated biomass samples. Clearly, significant europium signals can be detected already after $6.5 \mathrm{~h}$ of incubation, indicating, that europium is enriched and accumulated in the biomass

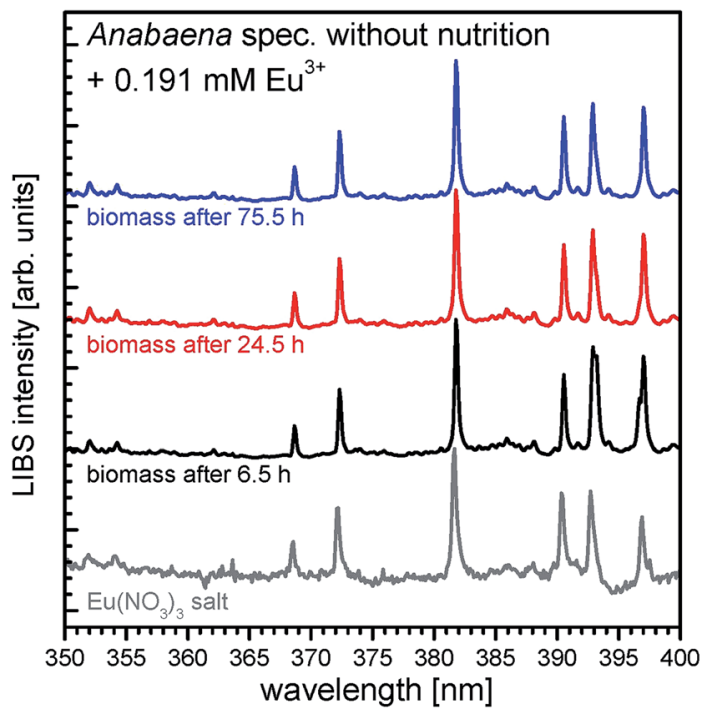

Fig. 3 LIBS spectra in the wavelength range from 350 to $400 \mathrm{~nm}$ of Anabaena spec. exposed to $0.191 \mathrm{mM} \mathrm{Eu}^{3+}$ taken after $6.5 \mathrm{~h}$ (black line), $24.5 \mathrm{~h}$ (red line) and $75.5 \mathrm{~h}$ (blue line) of incubation, and LIBS spectra of europium nitrate for comparison (grey line). after a short time and remains trapped there. Also longtime incubated samples show the specific europium signals, meaning an uptake and accumulation in the biomass samples. Hence, these results confirm the first conclusions drawn from ICP-MS measurements, which suggested a fast uptake of $\mathrm{Eu}^{3+}$ and further support the biosorption process for Anabaena spec. Although LIBS is a very sensitive tool for qualitative elemental analysis, it is up to now not applicable for a quantitative elemental analysis in these experiments. Without inevitable sample calibration neither peak intensities nor corresponding peak areas in the spectra provide reliable information about the amount of the analyte of interest. Hence, it is not possible to gather an absolute or even relative concentration level of europium or other elements in the biomass sample from the LIBS spectra.

In Fig. 4 the resulting LIBS spectra of the samarium experiments are shown. The spectra of neat Anabaena cylindrica (green line), incubated with $0.139 \mathrm{mM} \mathrm{Sm}^{3+}$ for $200 \mathrm{~h}$ (red bold line) and the pristine $\mathrm{Sm}\left(\mathrm{NO}_{3}\right)_{3} \cdot 6 \mathrm{H}_{2} \mathrm{O}$ (red thin line) are presented horizontally stacked for the ease of comparison. Emission peaks being characteristic for samarium (according to the NIST database $\mathrm{e}^{36}$ ) are indicated at the following wavelengths: $356.5 \mathrm{~nm}, 358.9 \mathrm{~nm}, 363.6 \mathrm{~nm}$, and $388.2 \mathrm{~nm}$. Both, peak position as well as the shape of the signals in the $\mathrm{Sm}^{3+}$ incubated biomass spectrum, e.g. the emission peak at $363.6 \mathrm{~nm}$, match the reference spectrum. With this result, it is proven that the incubated biomass contains samarium even $200 \mathrm{~h}$ after metal salt addition. As expected, no samarium is detected in the neat and untreated sample of Anabaena cylindrica.

Finally, also neodymium is found in the relevant samples of incubated Anabaena cylindrica. Fig. 5 shows the respective LIBS spectra of untreated Anabaena cylindrica (green line), incubated with an overall concentration of $0.103 \mathrm{mM} \mathrm{Nd}^{3+}$ (blue bold line)

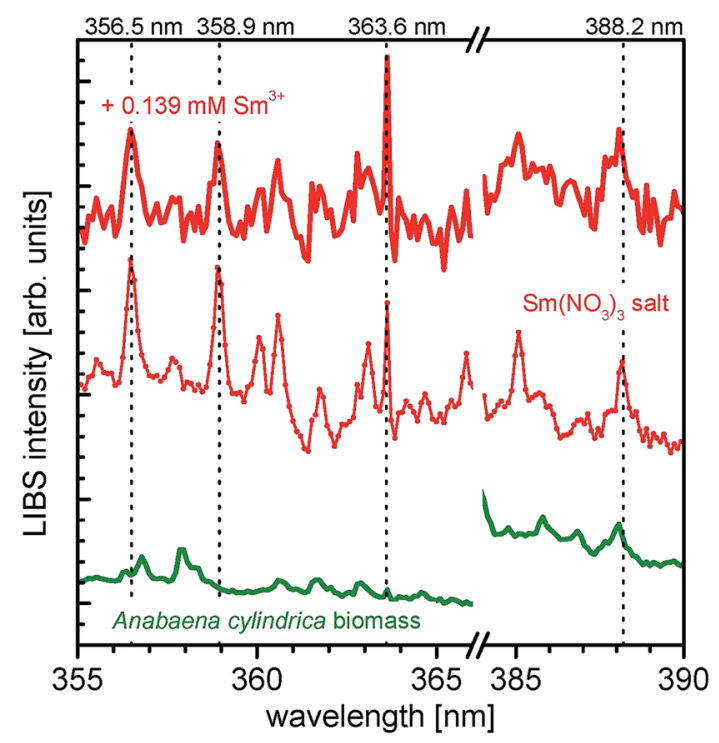

Fig. 4 LIBS spectra of Anabaena cylindrica exposed to $0.139 \mathrm{mM} \mathrm{Sm}^{3+}$ (red bold line) for $200 \mathrm{~h}$, Anabaena cylindrica biomass without metal salt (green) and spectra of samarium nitrate salt for comparison (red thin line). Emission peaks being characteristic for samarium are indicated. Please note: all spectra are stacked for clarity reasons. 
and the pristine $\mathrm{Nd}\left(\mathrm{NO}_{3}\right)_{3} \cdot 6 \mathrm{H}_{2} \mathrm{O}$ (blue dotted line) used as neodymium source for the biosorption experiments. Neodymium specific emission peaks (according to NIST database $^{36}$ ) are indicated at the wavelengths of $373.4 \mathrm{~nm}, 378.0 \mathrm{~nm}$, $380.2 \mathrm{~nm}, 386.0 \mathrm{~nm}, 400.9 \mathrm{~nm}$, and $405.8 \mathrm{~nm}$, respectively. These signals, although with low intensity, are found in the incubated biomass sample, already after 11 hours of metal salt addition as well as after longer times. Especially for the rare earth element neodymium the signal intensities are generally very low, as can be deduced from the reference spectrum of neodymium(III) nitrate. Nevertheless, it is obvious that the incubated Anabaena cylindrica sample contains neodymium, which was biosorbed from the surrounding media. As expected, no neodymium is found in the untreated Anabaena culture.

These first results show, that the tested REE are biosorbed almost entirely by the two cyanobacterial strains Anabaena spec. and Anabaena cylindrica. In addition, it was intended to check if a possible accumulation of REE in the manner of particle or cluster formation occurs.

\section{TEM}

To evaluate a possible particle formation, similar to the gold particle formation experiments performed with Anabaena spec. and Anabaena cylindrica in our previous studies ${ }^{30,31}$ samples were taken at different times of the particular experiment. The importance of heterocysts for the biosynthesis of metallic particles is widely discussed (see introduction), therefore a comparative analysis for vegetative cells (VC) and heterocysts (HC) was done. Large TEM image sections of Anabaena spec. and Anabaena cylindrica are given in Fig. 6 and show these typical cells.

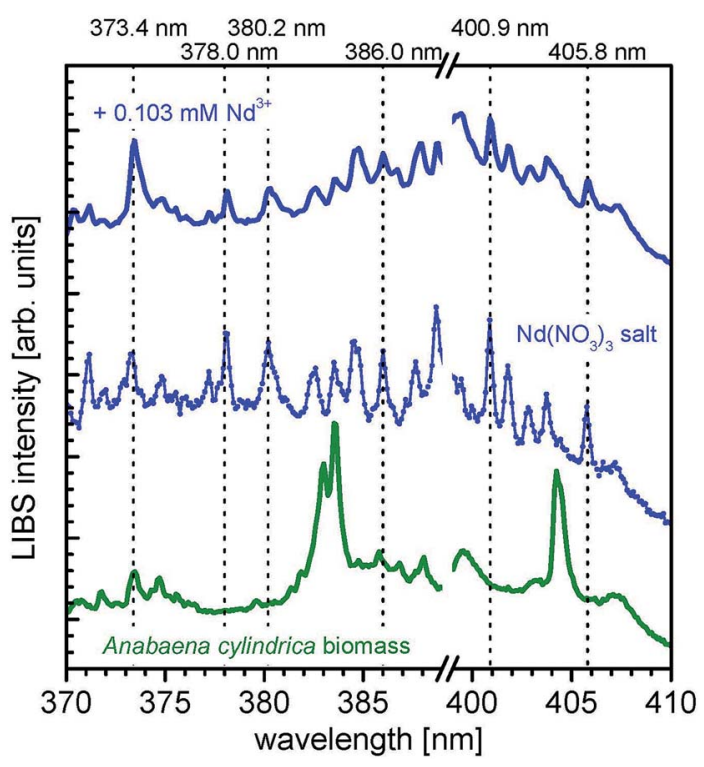

Fig. 5 LIBS spectra of Anabaena cylindrica exposed to $0.103 \mathrm{mM} \mathrm{Nd}^{3+}$ (blue line) taken after 24 hours of incubation, Anabaena cylindrica without any metal salt (green curve) as biomass reference and LIBS spectra of neodymium nitrate for comparison (blue dotted line). Emission peaks being characteristic for neodymium are indicated. Please note: all spectra are stacked for better visibility.
Fig. 7 shows enlarged TEM sections of a representative HC (Fig. 7A) and a representative VC (Fig. 7B) of Anabaena spec. prior to europium addition, respectively. Typical cell compartments for vegetative cyanobacterial cells, especially plenty of thylakoid membranes (Th), gas vacuoles (GV), DNA containing regions with fine fibrils (D) and electron dense spots, most probably representing lipid droplets (L), all surrounded by the cell wall and a mucilage (M) of exopolysaccharides (EPS) with fibrous structure ${ }^{41}$ are visible. However, the $\mathrm{HC}$ contains residual and therefore less densely packed thylakoids as well as lipid droplets. The HC is surrounded by a heterocyst polysaccharide layer (HEP). ${ }^{41}$ This HEP is thicker at the cell ends next to other cells, but visible all around the cell. Compared to the EPS the HEP is generally much thicker and is clearly visible in Fig. 7A.

TEM images of Anabaena spec. incubated for $10 \mathrm{~h}$ or $28 \mathrm{~h}$ with a total concentration of $0.111 \mathrm{mM} \mathrm{Eu}^{3+}$ are presented in Fig. 8. Sections of a heterocyst are displayed in panels A, B, D and $\mathrm{E}$; image sections of a vegetative cell are displayed in panels $\mathrm{C}$ and $\mathrm{F}$. Interestingly, only inside the HC many small black dots appear all over the cell. These electron dense spots obviously indicate the formation of europium particles already within the $10 \mathrm{~h}$ of metal salt incubation and are still detectable after $28 \mathrm{~h}$. As can be seen from the images, there is no preferred region or cell structure inside the $\mathrm{HC}$ in which these particles are located and therefore we assume they are statistically distributed within the cell. No particles can be seen outside the HC, i.e. the HEP. Within the higher magnification (E) the particles show a wide size distribution and appear mainly with an irregular and diffuse shape. The largest particles have a size of around $15 \mathrm{~nm}$ in diameter. Particles with a size of less than $4 \mathrm{~nm}$ can hardly be detected in these ultrathin sections due to the electron dense background caused by the heavy metal stained biomass. Concerning the VC no such particles or accumulations can be seen, nor inside the VC neither outside, i.e. in the EPS, at any time.

After $28 \mathrm{~h}$ of incubation about the same amount of particles can be detected compared to the results after $10 \mathrm{~h}$. One can estimate a similar particle size distribution as well as a similar irregular shape of the particles in comparison to the ones detected after $10 \mathrm{~h}$ from the micrographs. Also the maximum particle size seems to be unchanged. No particles can be seen outside the HC, i.e. the HEP.

The estimated particle sizes and their size distribution inside the $\mathrm{HC}$ are presented in Fig. 9 for the incubation times of $10 \mathrm{~h}$ and $28 \mathrm{~h}$, respectively. About the same number of particles were found and analyzed in the TEM images, with a slightly higher number being observed after $10 \mathrm{~h}$. Smaller average particle sizes were found after longer incubation times (i.e. 53 $\mathrm{nm}^{2}$ for $10 \mathrm{~h}$ and $34 \mathrm{~nm}^{2}$ after $28 \mathrm{~h}$ ) than after shorter incubation time. As can be seen, highest fractions are attributed to very small particles of about $4 \mathrm{~nm} .{ }^{2}$ Since TEM analysis requires the removal of ongoing aliquots from the culture, it is impossible to observe identical cells at different times after incubation. Therefore, these differences in the mean area can be explained as differences between cells, or simply due to technical conditions of image recording. Another source of error is the possible release of particles from the cells, since the 


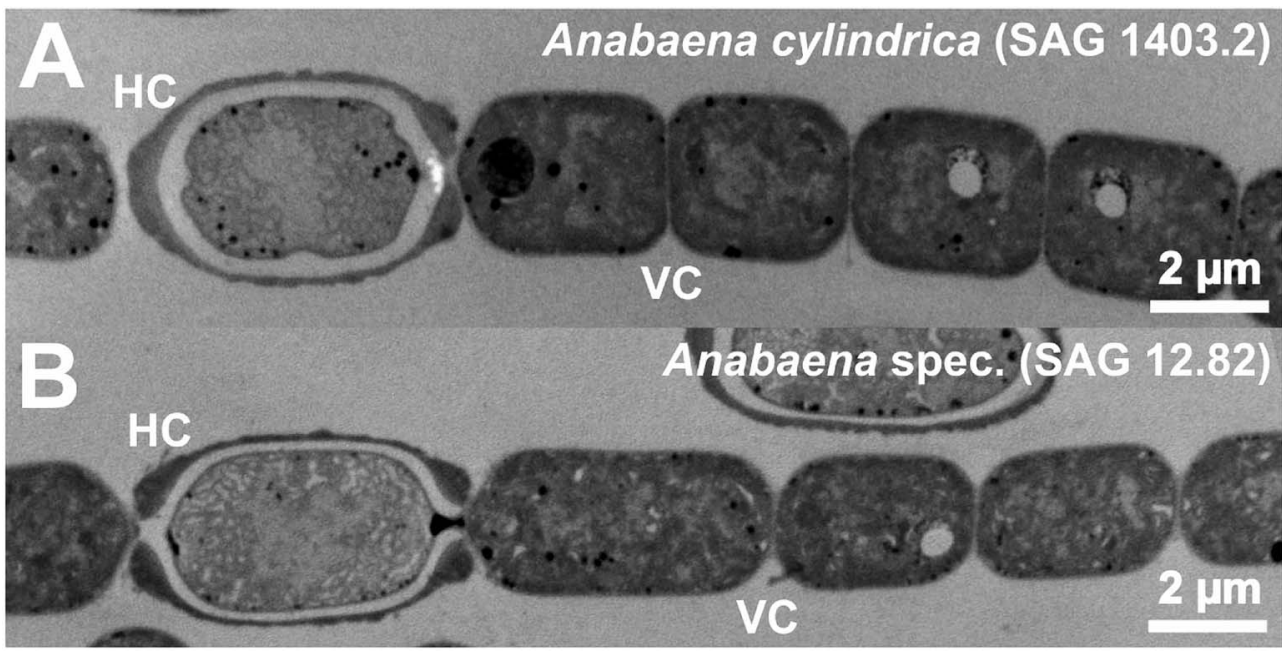

Fig. 6 TEM micrographs of Anabaena cylindrica (A) and Anabaena spec. (B) each presenting a heterocyst (HC) and several vegetative cells (VC).

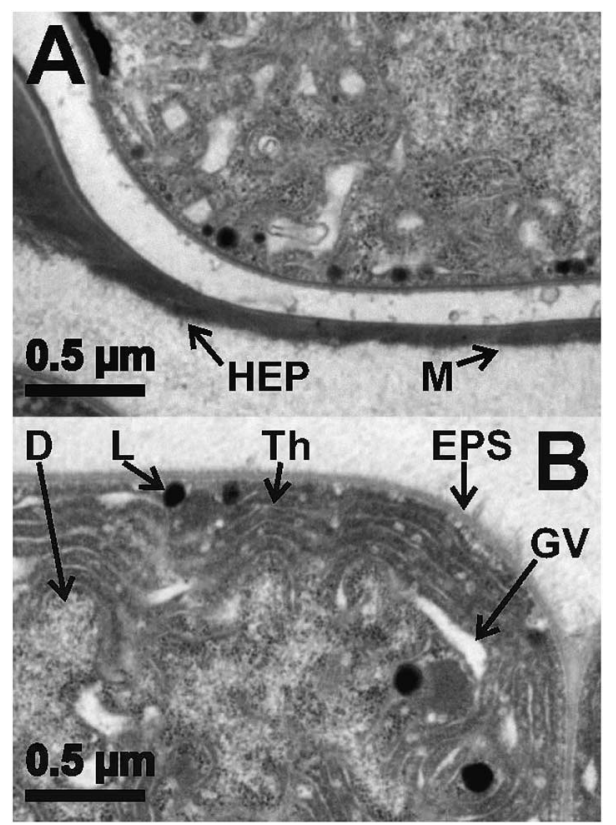

Fig. 7 Enlarged TEM micrograph sections of a representative heterocyst (A) and a representative vegetative cell (B) of Anabaena spec. without any addition of $\mathrm{Eu}^{3+}$ as a reference. Typical cyanobacterial cell compartments such as thylakoid membrane (Th), gas vacuole (GV), DNA containing region with fine fibrils (D), lipid droplet (L) as well as the heterocyst polysaccharide layer (HEP) and the mucilage (M) can be identified.

samples were washed for TEM analysis, so that only particles remaining in the cells are detected in these measurements.

Furthermore, after 10 days of incubation with an overall concentration of $0.111 \mathrm{mM} \mathrm{Eu}^{3+}$, the TEM images of Anabaena spec. reveal still the same result: particles only inside the HC and none in the VC (images not shown here).

Amongst the rare earth elements examined in this studied, within the europium series particles of several nanometers in size could be achieved by the presented biosynthetic route and the use of Anabaena spec. This is interesting, since in all experimental setups all the REE have quiet effectively been removed from the aqueous solution (see ICP-MS results in Fig. 1). Therefore, it could be assumed also for the others.

\section{XRD}

Finally, XRD measurements were performed to gather both, information about crystallinity and a more precise average particle size. Since the europium series revealed the effective formation of particles, respective biomass samples were examined by XRD.

Interestingly, none of the europium incubated biomass samples showed any reflections in the XRD. Hence, all the samples did not contain any crystalline europium particles. More precisely: neither in an early stage (after $6 \mathrm{~h}$ ) nor in an intermediate state $(28 \mathrm{~h}$ ) nor in an advanced stage (after $200 \mathrm{~h}$ ) of the experiments, a crystallinity of the particles could be proven by current XRD measurements. Therefore, their structure has to be considered to be a non-crystalline one. Consequently, there is convincing evidence that the TEM-detected particles are presumably of an amorphous nature.

Since no Bragg reflections could be detected in these measurements, no determination and calculation of the average crystallite particle size by the use of the Scherrer-equation were possible. Furthermore, as the instrumental XRD setup used here is capable of detecting crystalline particles with an average size of as low as $1.5 \mathrm{~nm}$ and as TEM analysis yielded $15 \mathrm{~nm}$ sized particles, a possible hampered analysis due to a resolution limitation of the diffractometer can be excluded.

\section{Discussion}

This study adds valuable results on the ongoing work in the research field on Anabaena spec. and Anabaena cylindrica and their biosorptive capabilities towards the rare earth elements $\mathrm{Eu}, \mathrm{Sm}$ and Nd. 


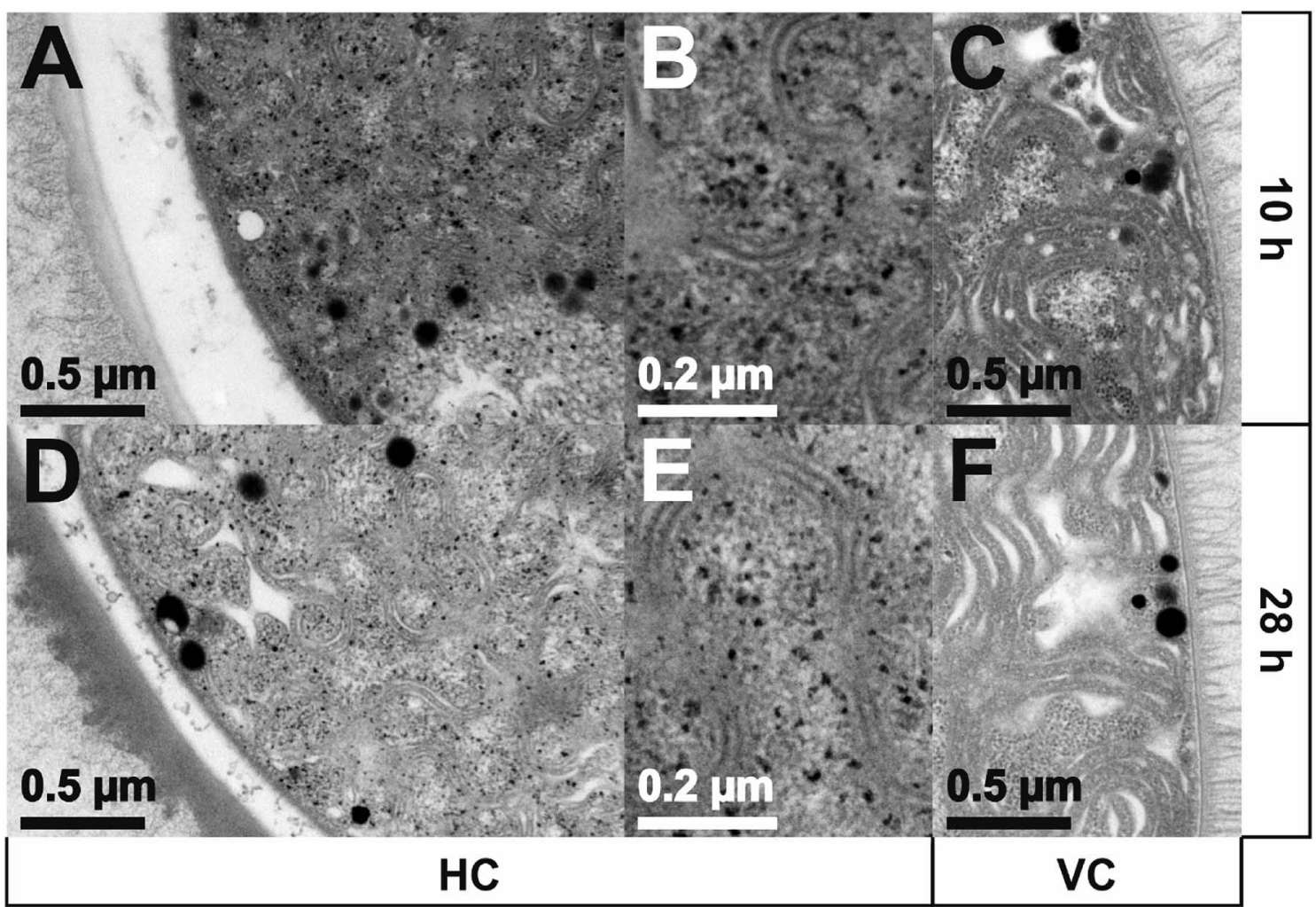

Fig. 8 TEM images of Anabaena spec. incubated with an overall concentration of $0.111 \mathrm{mM} \mathrm{Eu}^{3+}$ for $10 \mathrm{~h}$ and $28 \mathrm{~h}$, respectively. Sections of a heterocyst $(\mathrm{HC})$ are displayed in panels $A, B, D, E$, sections of a vegetative cell (VC) are displayed in panels $C$ and $F$.

The cyanobacteria strain Anabaena spec. is able to biosorb in vivo the trivalent $\mathrm{REE} \mathrm{Eu}^{3+}$ from aqueous solutions and to form intracellularly europium particles. Similar features for Anabaena spec. as well as Anabaena cylindrica and the addition of gold have recently been reported by some of the authors. ${ }^{30,31}$ Furthermore, Anabaena cylindrica was found to be highly selective towards the formation of gold nanoparticles in the presence of rhodium and iridium. ${ }^{32}$ Although, these and further

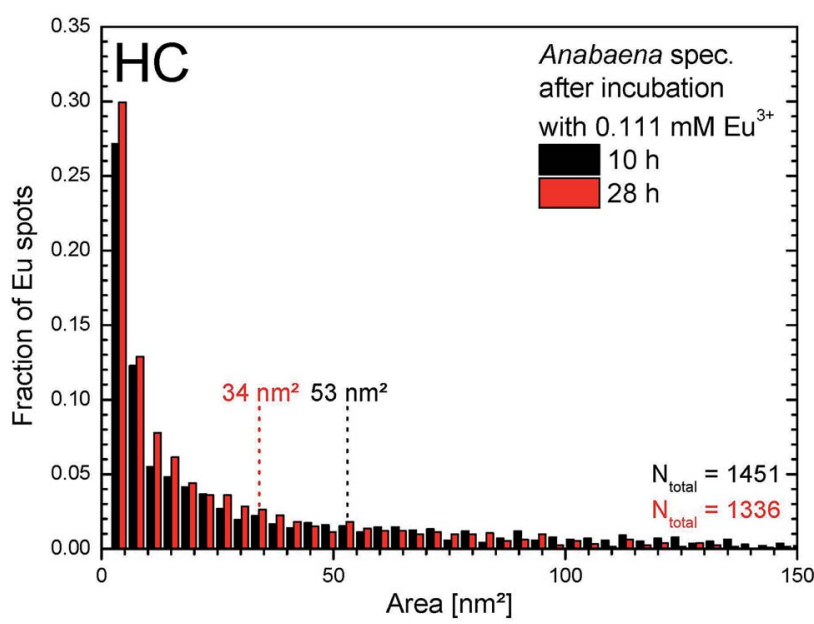

Fig. 9 Size distribution of europium particles obtained from TEM images within $\mathrm{HCs}$ of Anabaena spec. after $10 \mathrm{~h}$ and $28 \mathrm{~h}$ of incubation with $0.111 \mathrm{mM} \mathrm{Eu}^{3+}$, respectively. studies reported on the subsequent nanoparticle formation of precious metals also using other cyanobacterial strains (e.g. Anabaena flos-aquae ${ }^{\mathbf{2 8 , 4 2}}$, the formation of REE particles, however, by living cyanobacteria has never been reported yet.

The second cyanobacterial strain used within this study, Anabaena cylindrica, is capable to efficiently extract the rare earth elements samarium and neodymium from (highly) diluted aqueous solution, in the meaning of a biosorption process. Hence, this partial outcome is in line with various other studies, also describing solely the biosorption capability of biomass towards diluted REE (see introduction).

In contrast to Anabaena flos-aquae, the presently used strains Anabaena spec. (SAG 12.82) and Anabaena cylindrica (SAG 1403.2) do not produce and release anatoxin-a, which is a major advantage. ${ }^{43}$ Furthermore, these two cyanobacteria representatives are undemanding organisms and they are easy to handle in terms of cultivation as well as biosorption and possibly bioreduction. They can even withstand to some extend malnutrition for several days and weeks, whilst still being able to biosorb and intracellularly retain REE.

The biosorption process, i.e. the decrease of $\mathrm{REE}^{3+}$ concentration in the aqueous media due to the uptake by biomass, was tracked by ICP-MS and LIBS. From ICP-MS analysis one can estimate that upon exposure to a $\mathrm{REE}^{3+}$ solution biosorption starts immediately. Within the first hour of incubation almost the entire (>99\%) $\mathrm{REE}^{3+}$ amount is removed from the media. LIBS was used to prove the biomass as the sorbent of the REE. 
Especially for the europium series, ICP-MS analysis shows that biosorption starts immediately upon exposure to an overall concentration of $0.111 \mathrm{mM}$ of $\mathrm{Eu}^{3+}$. After the first hour of incubation only $0.6 \%$ of the initial $\mathrm{Eu}^{3+}$ concentration was still detectable in the supernatant (i.e. only $76 \mathrm{ppb}$ left). This, in turn, means that within this time almost the entire $\mathrm{Eu}^{3+}$ amount (i.e. up to 99.4\%) is removed from the media. Experiments with concentrations approximately twice as high (i.e. $0.191 \mathrm{mM} \mathrm{Eu}^{3+}$ ) were tolerated by the biomass as well and gave similar results. A reduction of $\mathrm{Eu}^{3+}$ concentration by about $75 \%$ after 40 minutes was determined and an almost total uptake of dissolved europium ions was determined after $3 \mathrm{~h}$. These results are quite impressive, since these experiments in this higher concentration range were performed in the absence of any nutrient medium. However, biosorption is more effective when experiments are performed in culture media rather than in a starving culture, proving biosorption is an active in vivo process.

The results imply for both experiments a very fast biosorption process for Anabaena spec. within the low $\mathrm{Eu}^{3+}$ concentration range observed in this study. This corroborates the general idea of describing biosorption as a process with rapid kinetics. ${ }^{\mathbf{4} 23}$ Furthermore, the ICP-MS measurements confirm that no significant release of europium occurs once it is biosorbed.

The accumulation of europium in the biomass was qualitatively proven by LIBS. Altogether six characteristic peaks in the LIBS spectra of the europium incubated biomass sample could uniquely be assigned to europium (compare NIST data base). Additionally, these signals are in accordance with LIBS spectra obtained from the europium stock solution used for the experiments (See Fig. 3). However, LIBS experiments performed on $\mathrm{Eu}^{3+}$ incubated biomass samples confirmed the deduction from ICP-MS analysis: the vast majority of biosorption proceeds within the first hour after europium addition. A potential temporal development meaning an increase of Eu concentration in the biomass during the experiment cannot be deduced from LIBS data. Since the signal intensities are not necessarily connected to a concentration value, it is not possible to conclude any (absolute or relative) concentration value of the analyte of interest. A quantification of the biosorbed europium with LIBS was not possible at this point and is generally still challenging up today for this kind of experiments.

Characterization of the Eu deposits was done ex situ by TEM and XRD. With TEM electron dense particles were localized only inside the cells of Anabaena spec., in particular only inside their heterocysts. Furthermore, these particles were statistically distributed inside the entire heterocyst instead of being preferentially located at the thylakoids. These results are somehow surprising and in sharp contrast to our previous findings, ${ }^{\mathbf{3 0 , 3 1}}$ where the thylakoid membranes of the vegetative cells were preferred deposits of biosynthesized gold nanoparticles. They even differ from the results found by Rochert et $a l^{32}$ who identified the HEP as the preferred region for gold nanoparticle formation from multimetall solutions. Recently, Dahoumane et $a .^{\mathbf{4 4}}$ also demonstrated the key role of the thylakoid membranes during the biosynthesis of noble metal nanoparticles. With the help of TEM they confirmed on the favored localization (the so-called place of birth) of the first produced gold nanoparticles within the thylakoids of a micro-algae.

From TEM micrographs the maximum size of the europium particles was determined to be approximately $15 \mathrm{~nm}$ for all the times observed in our study. Needless to say, also smaller particles were detected, which leads to a broad size distribution throughout the whole experiment, similar to a potential law than a Gaussian distribution. As the maximum size is not increasing with time, the final maximum size of the biosynthesized particles must have been achieved before the first sampling after $10 \mathrm{~h}$. It is likely that the nucleation starts immediately after incubation and biosorption and moreover might be finished in the first few hours since all ions were removed from supernatant within one hour. Besides the size also the shape of the europium particles was characterized by TEM. The images revealed a more or less irregular shape of the particles with a diffuse, scarcely defined rim (see Fig. 8B and E). This leads to the assumption of the presence of agglomerated smaller particles and to the result which was finally found by XRD. With XRD analysis it was shown that the detected europium particles had an amorphous instead of a crystalline structure. Since the samples exhibited no Bragg reflections, no calculation of the particles' average size using the Scherrerequation was possible. Therefore, only a roughly estimated maximum size from TEM images instead of a precisely calculated average particle size from XRD was obtained. Although we had no device to analyze the oxidation state of the europium (e.g. by XPS, EDX), to reveal whether if it was reduced to zero or still has the initial oxidation state "III" or changed else, we assume the particles inside the heterocysts to be amorphous agglomerated europium particles. Via interactions of biomacromolecules present inside the $\mathrm{HC}$ an agglomeration of $\mathrm{Eu}^{3+}$ and finally stabilization of amorphous particles might proceed. Microbial products, $e$. g. metallothionein-like proteins are known to bind and sequester rare earth metals ${ }^{\mathbf{4 5}}$ and are also found in cyanobacteria. ${ }^{22,25}$ Mercogliano and DeRosier ${ }^{27}$ showed that in vitro synthesized metallothionein-gold nanoclusters are visible in TEM and reveal varying sized clusters. They stated more than 20 gold atoms to be bound to a single metallothionein molecule. Hence, it is likewise to assume a strong complexation of the biosorbed $\mathrm{Eu}^{3+}$ for the cyanobacterial strains used here. Cheng et al. ${ }^{46}$ recently demonstrated the adsorption and subsequent mineralization of lanthanum by Bacillus licheniformis, a Gram-positive bacterium commonly found in the soil. Conversion of amorphous La(III) adsorbed on cell surface phosphate groups to precipitated crystalline nanomineral monazite $(\mathrm{La})\left(\mathrm{LaPO}_{4}\right)$ occurred within 30 days. Prior to this conversion no crystalline phases were detected with XRD. Likewise, biomineralization of Sm(III) into monazite(Sm) on the outer cell-surface of Saccharomyces cerevisae and Pseudomonas fluorescens was shown by Jiang et al. ${ }^{47}$

In case of an ionic origin of the europium particles, means a salt-like precipitate (e.g. europiumhydroxide) inside the heterocysts, one would at least expect an evidence of large crystalline structures from XRD, what, however, was not confirmed in our study. 
In fact, no crystalline structure of the TEM detected europium particles can be approved. Due to the non-crystallinity and the missing information in terms of the oxidation state of the europium particles, we consciously avoid calling them nanoparticles in this context. In our understanding, at least crystallinity of the metal particles is a prerequisite feature for this designation.

Though the experiments with Anabaena cylindrica revealed, that the biosorption of the REE samarium and neodymium occurs, a particle formation could not be proven within these series. With ICP-MS it was clearly shown that samarium is removed by up to $99 \%$ within the first 20 minutes after the addition of an overall concentration of $0.139 \mathrm{mM} \mathrm{Sm}^{3+}$. After one hour $99.5 \%$ and moreover after $12 \mathrm{~h}$ more than $99.9 \%$ of the added samarium was removed from the media. A renewed increase of the samarium concentration, due to a possible rerelease, was not detected, much like in the europium series. Similar results were obtained for the biosorption of neodymium. In comparable timescales almost the same amount of neodymium was sorbed. The LIBS measurements gave in addition a clear evidence for the biosorption capabilities of Anabaena cylindrica towards $\mathrm{Sm}^{3+}$ and $\mathrm{Nd}^{3+}$. In the observed timescale of up to $200 \mathrm{~h}$, samarium and neodymium were unambiguously detected in each of the respective samples. Although no information about the REE concentration can be gathered from the LIBS data, one result can be stated without a doubt: samarium and neodymium are efficiently recovered from highly diluted aqueous solutions by the biomass. In combination with the ICP-MS measurements which reveal no re-release of already sorbed species also the cyanobacteria strain Anabaena cylindrica can be referred to as an efficient and reliable biosorbent towards REE, especially for $\mathrm{Sm}^{3+}$ and $\mathrm{Nd}^{3+}$.

Within this study, we obtained in a first instance comparable results for both, Anabaena spec. and Anabaena cylindrica concerning their ability to biosorb the dissolved trivalent REE species, i.e. $\mathrm{Eu}^{3+}, \mathrm{Sm}^{3+}$ and $\mathrm{Nd}^{3+}$. The biosorption process proceeds in all cases quite fast within a few minutes after metal salt addition. Impressively, within such a short time, almost the entire $\mathrm{REE}^{3+}$ amount was removed from the surrounding media by the biomass. The exact mechanism responsible for the REE entrapment is not clear, and not the subject of interest here either. Nevertheless, one can state, that there has to be a quite effective metal binding towards these REE, since no leaching and re-release of these species was detected even after more than several weeks. Moreover, it was shown that at least the accumulation of europium must proceed via an active, metabolism-dependent process, since the intracellular uptake and the internalization of metal, which was demonstrated by TEM, requires microbial activity ${ }^{\mathbf{4} 48}$ in the short time span within this experiment.

The observed intracellular uptake of europium and formation of particles is highly interesting and somehow surprising, since biosorption is commonly attributed to proceed on the outer cell wall and particularly via the extracellular polymeric substances. In case of the cyanobacteria and especially their heterocysts the internalization at least for europium has to be a privileged route over cell wall adsorption, since europium particles are solely detected inside the HCs but never seen on the outside. As already mentioned, we assume the particles to be biomolecule-complexed europium species in their initial ionic state. This is based on many respects:

First, since a rather random distribution all over the interior of the HC instead of a favored localization next to the thylakoids (as expected from our previous study and other studies, which call them nanoparticles' place of birth ${ }^{\mathbf{4 4}}$ ) is observed, we cannot claim a possible bioreduction leading to $\mathrm{Eu}^{0}$ as well as a subsequent formation of europium nanoparticles. Second, the absence of characteristic reflections in XRD, provides convincing evidence for an amorphous origin of the observed europium particles. The presence of crystalline europium nanoparticles is therefore excluded. However, due to the detection by TEM, the particles (have to) exhibit a much higher electron density, which means a lot of heavy metal atoms, in comparison to the surrounding biomass. Besides the already excluded possible presence of metallic nanoparticles, a high electron density may also originate from an agglomeration and therefore densification of a high amount of europium by biomacromolecules, most likely proteins, present in the cells. Caused by the inherent size and structure of these organic chelators, the assumption may also explain the irregular shape and diffuse rim of the particles visualized by TEM. Moreover, also the random distribution of the particles inside the HC justifies this agglomeration theory, since the macromolecules are freely available inside the cytoplasma. Furthermore, due to the high redox potential generally known for (trivalent) REE species $\left(\right.$ e.g. $\mathrm{Eu}^{3+} \rightarrow \mathrm{Eu}^{0}\left(E_{0}=-1.991 \mathrm{~V}\right), \mathrm{Sm}^{3+} \rightarrow \mathrm{Sm}^{0}\left(E_{0}=\right.$ $-2.304 \mathrm{~V})$ and $\left.\mathrm{Nd}^{3+} \rightarrow \mathrm{Nd}^{0}\left(E_{0}=-2.323 \mathrm{~V}\right)\right)^{49}$ a bioreduction in the sense of an enzyme mediated electron transfer and therefore the formation of zero-valent REE species is hardly reasonable.

At least for the previously shown gold nanoparticle formation by these two cyanobacteria ${ }^{30}$ a differing behavior was not experienced. If one assumes the two strains to show the same behavior towards the REE, the resulting differences in particle formation have to be caused by the single REE itself or its particular and individual interaction inside the cell. The three REE species are all of trivalent state and originate all from the corresponding REE nitrate hexahydrate compounds $\mathrm{REE}\left(\mathrm{NO}_{3}\right)_{3} \cdot 6 \mathrm{H}_{2} \mathrm{O}$. Differing transport processes inside the cell, various ionic radii of the $\mathrm{REE}^{3+}$ as well as their hydrated equivalents and slightly differing redox potentials (see above) may be possible explanations but lack for further investigation.

\section{Conclusion}

The two cyanobacterial strains Anabaena spec. and Anabaena cylindrica both are capable to actively biosorb the rare earth elements europium, samarium, and neodymium from highly diluted ( $\mu \mathrm{M}$ range) aqueous solutions. The uptake by biomass proceeds very fast and almost complete. Within the first hour after REE addition more than 99\% of the initial REE concentration is biosorbed by the cyanobacteria. Moreover, it was shown that Anabaena spec. accumulates and incorporates europium particles. These particles were detected by TEM only 
inside the heterocysts, neither outside the heterocysts nor in or outside the vegetative cells. TEM revealed maximum particle sizes of about $15 \mathrm{~nm}$. The particles are evenly spread over the interior heterocyst and show no preferred localization (e.g. at the thylakoid membranes) within the cells. With XRD analysis it was shown that the europium particles had a non-crystallite structure. Since the samples exhibited no Bragg reflections, no determination of the particles' average size via XRD was possible.

However, Anabaena spec. and Anabaena cylindrica have been proven to be efficient and environmental friendly biosorbents for the enrichment of rare earth elements, europium, samarium and neodymium from diluted aqueous solutions. Nevertheless, further research is needed in the area of "harvesting" the accumulated REE particles and a subsequent sustainable recycling option. On the other hand, possible implementations of cyanobacteria-supported REE-collecting steps in municipal wastewater treatment plants or recovery stations in running waters and rivers are future perspectives.

\section{Conflicts of interest}

There are no conflicts to declare.

\section{Acknowledgements}

The authors gratefully acknowledge the financial support provided by Deutscher Akademischer Austauschdienst (DAAD) through the project PPP 57445545. We thank Lars Düster, Björn Meermann, Michael P. Schlüsener, Thomas A. Ternes, (Federal Institute of Hydrology, BfG, Koblenz) and Sander van Smaalen (Laboratory of Crystallography, University of Bayreuth) for analytical support as well as Rita Grotjahn and Romina Bachstein (Cell Biology, Electron Microscopy, University of Bayreuth) for technical assistance.

\section{References}

1 S. Kulaksız and M. Bau, Environ. Int., 2011, 37, 973-979.

2 S. Kulaksiz and M. Bau, Earth Planet. Sci. Lett., 2013, 362, 4350.

3 R. C. Oliveira, E. Guibal and O. Garcia Jr, Biotechnol. Prog., 2012, 28, 715-722.

4 T. Macek and M. Mackova, in Microbial Biosorption of Metals, ed. P. Kotrba, M. Mackova and T. Macek, Springer Netherlands, 2011, ch. 2, pp. 7-17.

5 D. Park, Y. S. Yun and J. M. Park, Biotechnol. Bioprocess Eng., 2010, 15, 86-102.

6 H. Moriwaki and H. Yamamoto, Appl. Microbiol. Biotechnol., 2013, 97, 1-8.

7 F. Veglio and F. Beolchini, Hydrometallurgy, 1997, 44, 301316.

8 P. Kotrba, in Microbial Biosorption of Metals, ed. P. Kotrba, M. Mackova and T. Macek, Springer Netherlands, 2011, ch. 1, pp. 1-6.

9 P. Kotrba, M. Mackova and V. Urbánek, Microbial Biosorption of Metals, Springer Netherlands, 2011.
10 Y. Takahashi, X. Chatellier, K. H. Hattori, K. Kato and D. Fortin, Chem. Geol., 2005, 219, 53-67.

11 R. E. Martinez, O. Pourret and Y. Takahashi, J. Colloid Interface Sci., 2014, 413, 106-111.

12 Y. Andres, A. C. Texier and P. Le Cloirec, Environ. Technol., 2003, 24, 1367-1375.

13 Y. Andrès and C. Gérente, in Microbial Biosorption of Metals, ed. P. Kotrba, M. Mackova and T. Macek, Springer Netherlands, 2011, ch. 8, pp. 179-196.

14 H. Moriwaki, R. Koide, R. Yoshikawa, Y. Warabino and H. Yamamoto, Appl. Microbiol. Biotechnol., 2013, 97, 37213728.

15 J.-A. Kim, G. Dodbiba, Y. Tanimura, K. Mitsuhashi, N. Fukuda, K. Okaya, S. Matsuo and T. Fujita, Mater. Trans., 2011, 52, 1799-1806.

16 C. Acharya, P. Chandwadkar and S. K. Apte, Bioresour. Technol., 2012, 116, 290-294.

17 R. De Philippis, G. Colica and E. Micheletti, Appl. Microbiol. Biotechnol., 2011, 92, 697-708.

18 M. K. Okajima, S. Miyazato and T. Kaneko, Langmuir, 2009, 25, 8526-8531.

19 M. K. Okajima, T. Higashi, R. Asakawa, T. Mitsumata, D. Kaneko, T. Kaneko, T. Ogawa, H. Kurata and S. Isoda, Biomacromolecules, 2010, 11, 3172-3177.

20 A. S. Ayangbenro and O. O. Babalola, Int. J. Environ. Res. Public Health, 2017, 14, 94.

21 K. Kuroda and M. Ueda, Appl. Microbiol. Biotechnol., 2010, 87, 53-60.

22 A. Gupta, B. A. Whitton, A. P. Morby, J. W. Huckle and N. J. Robinson, Proceedings: Biological Sciences, 1992, 248, 273-281.

23 M. Pazirandeh, L. A. Chrisey, J. M. Mauro, J. R. Campbell and B. P. Gaber, Appl. Microbiol. Biotechnol., 1995, 43, 1112-1117. 24 T. Berka, A. Shatzman, J. Zimmerman, J. Strickler and M. Rosenberg, J. Bacteriol., 1988, 170, 21-26.

25 J. Turner and N. Robinson, J. Ind. Microbiol., 1995, 14, 119125.

26 Q. Wang, J. Xu, Y. Zhu, B. Chai, A. Liang and W. Wang, Biol. Trace Elem. Res., 2011, 143, 1808-1818.

27 C. P. Mercogliano and D. J. DeRosier, J. Mol. Biol., 2006, 355, 211-223.

28 R. Brayner, H. Barberousse, M. Hernadi, C. Djedjat, C. Yepremian, T. Coradin, J. Livage, F. Fievet and A. Coute, J. Nanosci. Nanotechnol., 2007, 7, 2696-2708.

29 S. A. Dahoumane, C. Djediat, C. Yepremian, A. Coute, F. Fievet, T. Coradin and R. Brayner, J. Nanopart. Res., 2012, 14.

30 L. M. Rösken, S. Körsten, C. B. Fischer, A. Schönleber, S. van Smaalen, S. Geimer and S. Wehner, J. Nanopart. Res., 2014, 16, 1-14.

31 L. M. Rösken, F. Cappel, S. Körsten, C. B. Fischer, A. Schönleber, S. van Smaalen, S. Geimer, C. Beresko, G. Ankerhold and S. Wehner, Beilstein J. Nanotechnol., 2016, 7, 312-327.

32 A. S. Rochert, L. M. Rösken, C. B. Fischer, A. Schönleber, D. Ecker, S. van Smaalen, S. Geimer and S. Wehner, J. Nanopart. Res., 2017, 19, 355. 
33 C. Voica, M. H. Kovacs, A. Dehelean, D. Ristoiu and A. Iordache, Rom. J. Phys., 2012, 57, 1184-1193.

34 A. A. Ammann, J. Mass Spectrom., 2007, 42, 419-427.

35 R. Thomas, Practical Guide to ICP-MS, Marcel Dekker, Inc., New York, Basel, 1 edn, 2004.

36 A. Kramida, Y. Ralchenko, J. Reader and NIST ASD Team, NIST Atomic Spectra Database (ver. 5.1), National Institute of Standards and Technology, Gaithersburg, MD, USA, accessed Aug 20 2019, http://physics.nist.gov/asd.

37 R. Noll, Laser-Induced Breakdown Spectroscopy: Fundamentals and Applications, Springer Berlin Heidelberg, 2012.

38 A. De Giacomo, M. Dell'Aglio, O. De Pascale and M. Capitelli, Spectrochim. Acta, Part B, 2007, 62, 721-738.

39 H. Sobral, R. Sanginés and A. Trujillo-Vázquez, Spectrochim. Acta, Part B, 2012, 78, 62-66.

40 E. S. Reynolds, J. Cell Biol., 1963, 17, 208-212.

41 E. Flores and A. Herrero, Nat. Rev. Microbiol., 2010, 8, 39-50.
42 S. A. Dahoumane, C. Djediat, C. Yéprémian, A. Couté, F. Fiévet, T. Coradin and R. Brayner, J. Nanopart. Res., 2012, 14, 883.

43 J. K. Fawell, R. E. Mitchell, R. E. Hill and D. J. Everett, Hum. Exp. Toxicol., 1999, 18, 168-173.

44 S. Dahoumane, C. Yéprémian, C. Djédiat, A. Couté, F. Fiévet, T. Coradin and R. Brayner, J. Nanopart. Res., 2014, 16, 1-12. 45 Y.-S. Yun, K. Vijayaraghavan and S. W. Won, in Microbial Biosorption of Metals, ed. P. Kotrba, M. Mackova and T. Macek, Springer Netherlands, 2011, ch. 5, pp. 121-141.

46 Y. J. Cheng, L. Zhang, X. J. Bian, H. Y. Zuo and H. L. Dong, Environ. Sci. Pollut. Res., 2018, 25, 22334-22339.

47 M. Y. Jiang, T. Ohnuki and S. Utsunomiya, Geomicrobiol. J., 2018, 35, 375-384.

48 Z. Aksu, T. Kutsal, S. Gün, N. Haciosmanoglu and M. Gholaminejad, Environ. Technol., 1991, 12, 915-921.

49 CRC Handbook of Chemistry and Physics - Internet Version, ed. D. R. Lide, 2005. 